\title{
Transmission and Textual Variants: Divergent Fragments of Sappho's Songs Examined
}

\author{
Mark de Kreij
}

"New Philology" focuses on texts in their material and unique forms. The name comes from a movement initiated by American philologists working on mediaeval texts, who in the 1990 issue of Speculum argued for a more systematic analysis of the many different versions of mediaeval texts that have been transmitted. ${ }^{1}$ This focus on the divergence of texts, as opposed to the emphasis on reconstruction of an original Urtext, had already been advocated by Zumthor and Cerquiglini in the preceding decades, but was only now applied to a range of actual corpora. ${ }^{2}$ After an endorsement by the German mediaevalist Stackmann, "New Philology" became known to a wider audience, who realized its applicability to corpora other than mediaeval epic songs. ${ }^{3}$ The panel at the Text, Transmission, Reception conference in Nijmegen showed how New Philology may illuminate issues in textual corpora ranging from early antiquity to the twentieth century. After all, instability of texts is of all times, whether it manifests in different versions on a papyrus and in a manuscript, in multiple editions and translations of an eighteenth century novel, or in contemporary paper and digital editions.

Though the approach and main tenets may be similar for each period and genre, the salient issues differ significantly. In classical studies, the strength of New Philology lies in its ability to reveal the effects of different stages of textual transmission. ${ }^{4}$ This approach places the texts - that is the multiple actualizations of a text in all possible forms - first, in a more radical way than the majority of researchers in classics tend to do. From ancient papyri and inscriptions to late mediaeval manuscripts and fragments quoted within other works,

See the introduction by Nichols on pages 1-10 for a statement of intent.

2 Zumthor (1972) and (1983), Cerquiglini (1989).

3 Stackmann (1994).

4 In the field of classics, Gentili (1984) anticipated some of the tenets of New Philology. More recently, Lardinois (2006) discusses divergent versions of Solon's poetry transmitted in different sources. Likewise, Lardinois [forthcoming] is explicitly new-philological in its approach to texts of early Greek song.

(C) MARK DE KREIJ, 2015 | DOI 10.1163/9789004270848_003

This is an open access chapter distributed under the terms of the Creative Commons AttributionNoncommercial 3.o Unported (CC-BY-NC 3.o) License. 
the field of classical studies has a wealth of material at its disposal for this kind of research.

Historically, the tendency in classical philology has been to approach its rich corpus with the intention of reconstructing original texts. Each instantiation of a certain text is thus appreciated only insofar as it is helpful to that enterprise. However, it is almost impossible to reconstruct the original version of any text, and in the case of archaic and classical Greek texts there is no hope at all of establishing the original form; a situation that arises due to the non-existence of literature (as we know it today) before the fifth century BC. If texts were written down, they were not intended for publication and reading, but rather for conservation and re-performance. The texts that we regard as the "classics" of classical literature in this period were primarily works to be performed; be it the Homeric epics, the dramas by Aeschylus, Sophocles, and Euripides, or the lyric songs composed by Pindar, Alcaeus, or indeed Sappho, who composed songs on Lesbos in the sixth century BС. ${ }^{5}$

Modern editions of Sappho's songs have been pieced together from quotations in the works of other, later, authors and - more recently - from scraps of papyrus. The sources at our disposal, then, were written down no earlier than three hundred years after the supposed composition, while the majority dates from the Middle Ages. Moreover, they are no more than the textual component of a larger whole that once included music, a specific venue, and probably dance. Generally, the only residue of the songs' original nature is their metrical pattern, and sometimes not even that. ${ }^{6}$ The texts in our possession are very fragmentary, represent only one facet of the original performance of Sappho's songs, and are separated from the date of composition by a physical gap of at least three centuries, which raises the question: How may such inevitably compromised sources for Sappho's songs serve classical philologists? A tentative answer requires first a survey of the traditional philological research on the fragments of Sappho. Adducing two quotes of Sappho in second-century AD

5 See especially Andrew Ford's “From Letters to Literature. Reading the 'Song Culture' of Classical Greece" in Yunis (2003) 15-37.

6 Greek metre is based on the division of heavy and light syllables (or "long" and "short"). This fact may help our understanding of Sappho in two ways. Firstly, knowledge of the metres she used may help identify a specific metrical pattern even if we only have a fragmentary text. Secondly, some of Sappho's music was stanzaic, built out of repeated metrical - and probably melodic - patterns. If we have a large enough part of the song, it is possible to establish if the metrical pattern recurs consistently - even if we have never encountered that specific metre before. With these two tools, it becomes possible in some instances to establish the original metre, and note where the text departs from the pattern; these places then invite discussion. 
sources, I will probe the possibilities offered by, and challenges posed to, New Philology in the field of classics. In Sappho's case, while the later sources may point only minimally toward her original sixth century BC compositions, they provide tantalizing glimpses of the form of her songs in the early centuries of our era.

The problems with the textual tradition for Sappho arise from the fact that unlike for Homer, for example, no manuscript edition of Sappho's songs has survived from the Middle Ages. ${ }^{7}$ As a result we are reliant upon quotations in other texts, either transmitted on papyri or, mainly, in mediaeval manuscripts, upon fragments of papyri, which date from the third century BC to the fourth century AD, a piece of parchment (sixth century AD), and the Sappho ostrakon (or potsherd) that contains the fragment $2 \mathrm{~V}^{8}$ The fragmentary nature of the extant texts is, however, not the only problem we face when reconstructing Sappho's songs. Working on sixth-century BC Lesbos, Sappho probably composed her songs in a dialect that was far removed from the Greek of classical Athens, let alone that of later antiquity or the Middle Ages. This is reflected in the fact that the forms we find in the mediaeval indirect sources differ considerably from those found in early Lesbian inscriptions and in treatises by ancient grammarians. ${ }^{9}$

Editing Sappho's texts, then, has been a process of reconstruction for scholars from the outset. ${ }^{10}$ If the goal is to approach the original compositions as closely as possible, this method is indeed the only one available to us, but New Philology argues that reconstruction is not the only goal in classical philology. The reconstructive method is reliant upon later authors' competence in copying correct citations into their own texts, as well as on the accuracy of our knowledge regarding Sappho's metres and the Lesbian dialect. These presuppositions have had the effect that the divergent forms of Sappho's songs, as found in the great majority of sources, have been picked apart and reconstruct-

The same thing holds for the other Greek poets of the lyric canon, with the sole exception of Pindar. See Hadjimichael (2011) for a rich exposition on the early transmission of the early Greek lyric composers, as well as an analysis of its reception in the peripatetic scholars.

The edition referred to throughout is Voigt (1971). The original edition of the ostrakon is Papiri della Società Italiana XIII, 1300.

The two most recent works on the dialect of the Lesbian poets, by Hooker and A.M. Bowie, provide a framework that is based on inscriptional evidence and ancient descriptions of the dialect. This produces a set of rules that appears to have been followed quite closely by the ancient editors, at least as far as that is reflected in the papyrus evidence. Until the late nineteenth century Sappho's corpus was restricted to fragments transmitted in indirect sources. 
ed to fit the expected form of both dialect and metre. Those "divergent" fragments of Sappho have thus rarely been studied in situ. ${ }^{11}$

The bulk of the fragments of Sappho's songs are found as quotations in the works of later authors such as Plutarch (first-second century AD), Stobaeus (fifth century AD), and Athenaeus (second-third century AD), which bring with them a very particular problem for the textual critic. The relation between the host text and the quoted fragment is similar to a mise-en-abime, and it urges us to consider the interplay between the two very closely. After all, it is one thing to attempt to reconstruct an original song by Sappho with all the knowledge of metre and dialect we have now, and quite another to assume that, firstly, the author quoting her song in the second century AD had the same knowledge and, secondly, had the intention or even the opportunity to faithfully render the original. In practice, however, this effort is rarely made, and the two discourses are reconstructed as if they were completely separate texts. ${ }^{12}$

In the following, I adduce two fragments from the early centuries of our era that were both transmitted by more than one source and in divergent forms. Fragment 2 V., transmitted on a potsherd and as a quote within Athenaeus' Deipnosophistae, serves to put the basic challenges and opportunities of a newphilological approach in relief. Subsequently, another fragment transmitted in two different but roughly contemporary sources illustrates how a re-examination of variants may challenge a latent presupposition in the reconstructive philological approach, namely that (generally older) papyrus evidence trumps manuscript evidence.

In the Deipnosophistae, a work of wide-ranging scholarship, ${ }^{13}$ Athenaeus sets the scene of a banquet, introduces the learned men who attend, and imagines the conversations that would take place between them. He uses fictitious dialogues and speeches as a vessel for the exposition of his own knowledge. Topics range from food, to music, and to poetry, and thus a great deal of information is accumulated in the many pages of the Deipnosophistae. Arguably, most valuable to philologists are the numerous quotes from ancient authors, often transmitted only through this work.

The scene presented by Athenaeus brings to mind the practice of the symposion best known from classical Athens. Even though it went through

\footnotetext{
11 A lone exception is Nicosia (1976).

12 See page 31 with note 41 below.

13 Olson's 2006 Loeb edition presents an accessible edition along with a full English translation; see, however, page 31 below for a comment on his text. It must be noted that even the most complete manuscript $(\mathrm{A})$ is incomplete. It misses the first two books, part of the third, and a few pages here and there. These gaps are usually filled by using an epitome that was preserved intact.
} 
significant changes, the gathering after dinner to share poetry and song lived on in different forms until the end of antiquity. Aulus Gellius (second century AD) in his Attic Nights testifies, among others, to the probability that the singing of "Sapphic" songs was still an after-dinner activity even in the second century AD. ${ }^{14}$

Sappho's songs, with love and longing as their subjects in many cases, formed a fitting corpus for the symposiast in any period. ${ }^{15}$ It is thus no surprise to find parts of her work in this fictional symposion imagined by Athenaeus. Within his dinner scene, he quotes the following fragment, which itself invokes a symposiastic scene - a divine symposion, describing the mixing and pouring of nectar.

Athenaeus, Deipnosophistae $11.463 \mathrm{e}^{16}$

$$
\begin{aligned}
& \text { (...) } \dot{\varepsilon} \lambda \theta \dot{\varepsilon}, \mathrm{K} v \dot{\pi} \pi \rho,
\end{aligned}
$$

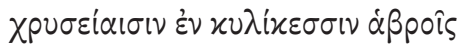

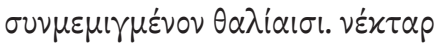

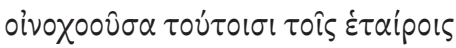

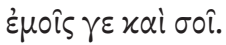

Come, Kypris, in golden cups [ ] mixed with gentle festivities, ${ }^{17}$ pouring nectar for these friends of mine and for yourself.

The quote in Athenaeus forms the end of a longer song, Sappho 2 in the Voigt edition, the largest part of which is preserved on the ostrakon. The text on the ostrakon was written in the third or second century BC while Athenaeus worked around $200 \mathrm{AD}$. The pottery shard gives a text that is written in an unclear hand,

\footnotetext{
14 Aulus Gellius, Attic Nights 19.9.3-7. For the singing of Sappho's songs in this time see also: Aelian fr. 190, in Stobaeus 3.29.58; Plutarch, Moralia, 611c and 722d.

15 Yatromanolakis gathers the relevant evidence for Sappho in Chapter 3 of his 2007 work. See Reitzenstein (1893), Collins (2004), and especially Vetta (1995) for an overview of our evidence for poetic practices at symposia.

16 The text as given here is the one found in Manuscript A (Venetianus Marcianus 447). Compare Olson 2009:V.224.

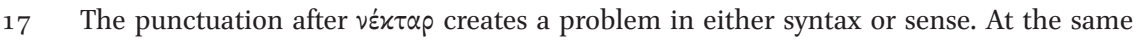
time it shows that the scribe of this manuscript believed the following line to be syntactically connected to the quote of Sappho.
} 
and what can be read is decidedly problematic with regard to both morphology and syntax. Athenaeus' version is problematic for different reasons, yet clearly related to the text on the ostrakon.

\section{Sappho Ostrakon ${ }^{18}$}

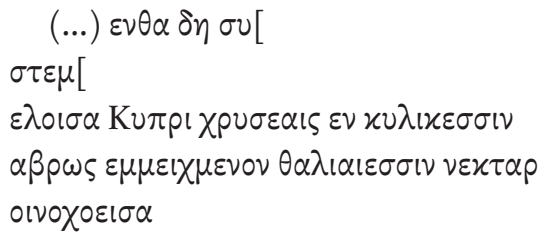

There you [were], holding [ ],

Kypris, skilfully pouring in golden cups

nectar mixed with

festivities

Without going into differences of dialect and orthography, the version on the ostrakon differs mainly from the version in Athenaeus in that it is part of a larger whole. This in itself leads to a different interpretation of the passage, but the difference between the two versions is also reflected in the language: where Athenaeus has the imperative "ह่ $\lambda \theta \hat{\varepsilon}$ " ["come"], the ostrakon has the participle

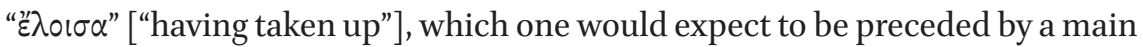
verb. Most striking of all, Athenaeus' text contains an extra line after the point where the ostrakon ends. As stated above the ostrakon is a potsherd, but it must be noted that the song was only written on this piece of pottery when it was already a sherd. The text is thus fairly complete, as far as we can establish, and the break-off point comes naturally after the end of a stanza, while there is still more room left to write on the potsherd had the writer wished it. The extra line in Athenaeus may either represent the start of a new stanza of the song (omitted from the ostrakon because only part of it would have fitted) or an addition, either composed by Athenaeus or already known to him in that form. The final text below is the fragment as given in Voigt's edition; a reconstruction which

18 PSI XIII, 1300. The reading of the ostrakon is extremely problematic. Different readers (Norsa, Theiler, Lanata, Lobel and Page) have all come up with different readings. As I have not been in a position to gain access to anything other than a (decent) photograph, I have decided to follow Norsa's reading. What is beyond doubt is that the ostrakon and Athenaeus do not give the same reading. For metrical reconstructions, see Norsa (1953) 47 and Lanata (1960) 89-9o and all modern editions of Sappho. 
makes use of both of these sources and is based on our knowledge of metre and dialect.

$$
\begin{aligned}
& \text { Voigt (1971) }
\end{aligned}
$$

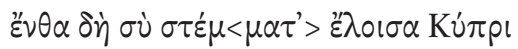

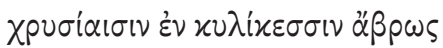

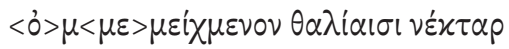

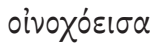

And there you [were], having taken up the wands, Cypris, skillfully pouring in golden cups, nectar mixed with festivities

The fact that the ostrakon is the earlier source is used by Voigt as a license to take its text as the basis for her reconstruction. Her edition, however, masks some significant differences between the two sources, both at the beginning and at the end of the fragment. As for the first four lines, we cannot know if the ostrakon version is the original rather than Athenaeus', as both fit the metre roughly and both could have made sense in the original. For the last line however, given in Athenaeus but not on the ostrakon, we are helped by the metre: it does not fit the reconstructed metrical schema in any way. It is thus highly unlikely to have been part of the song as Athenaeus knew it, and no surprise that Voigt omits it in her edition of Sappho.

For the provenance of this unmetrical line we might consider the following two possibilities. As noted above, Sappho's songs were most likely sung at symposia. These gatherings, like Athenaeus' literary reflection of it, formed opportunities to demonstrate one's erudition, literary prowess, poetic creativity, and wit. Apart from wine and song, poetic games formed an inherent part of these events, and part of the skill in these games was to remember, select, and adapt songs or poems by famous composers. The last line of the quote in Athenaeus suggests that it might be the result of such a creative adaptation. Symposia were predominantly male affairs, at least in the early stages in Attica. Sappho, however, seems to have written mainly for and about an audience consisting of a group of women. ${ }^{19}$ The last line of the quote by Athenaeus, then, is suspect

19 The nature of this group is open to much discussion, but does not concern us now. Cf. Parker (1993) Sappho Schoolmistress for a debunking of earlier theories, and Lardinois (1994) for a reaction to this article. 
not only because of the metrical problems, but also because of the gender of the "friends" mentioned. Sympotic uses of poetry and song were mostly in the form of quotations or passages rather than performances of whole works. I have no trouble imagining this stanza of a Sapphic song being adapted (the

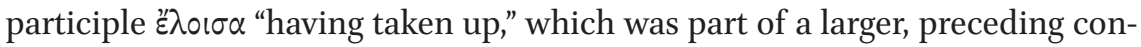
struction, changed to the imperative $\varepsilon \lambda \theta \varepsilon$ "come") and extended with an extra line to provide a fitting introductory quasi-prayer for a symposion of male aristocrats. Such an adaptation may then have ended up in a collection or an anthology of passages, quotes, and adaptations, such as we find in the papyrus containing the new Sappho poem. ${ }^{20}$

If this is too fanciful a proposition, the other possibility is that Athenaeus introduced the addition in his work both to show the workings of the symposion and to integrate the quote into his narrative. This latter is more attractive to a textually-oriented modern reader because a participant at a symposion might have been expected to make a metrically-fitting addition, whereas Athenaeus as an author of prose had no such restriction to deal with. It is unclear at which point Sappho's lyric began to be read as poetry, but I believe that by the first century AD the texts were still transmitted as songs, while also circulating as poetry for reading. However, the audience of the latter was not necessarily aware of the form that this "poetry" had in earlier times, or, if they were aware, either did not have the ability or the interest to reconstruct it.

Despite the noted textual problems, most of the fragment as quoted by Athenaeus still fits the metre reconstructed with the help of the longer fragment on the ostrakon. This should urge us to consider that divergences in form found in other fragments quoted by Athenaeus might have causes other than scribal error, such as earlier improvisation in performance, or literary adaptation by Athenaeus himself. Moreover, even though some evidence points to Sappho's songs still being in some way performed in the second century AD, ${ }^{21}$ the final added line suggests that there is no reason to assume that all of her work was still known in the form of songs at this time, or that the form remained consistent throughout subsequent centuries.

My analysis of the Sappho fragment above is open to one major point of criticism. Just like Sappho's songs, Athenaeus' work went through a process of transmission. Just like the texts of her songs, therefore, the tenth-century AD text that we have of his books is merely a reflection of his second-century composition. How can we be sure that this material is a reliable source for the form of Sappho's songs in Athenaeus' time? After all, if we can use the later 
manuscripts to establish or approach the original text by Athenaeus, why can we not do the same with the late sources for Sappho? We cannot, because the mode of transmission differs significantly for the fragments of Sappho's songs on the one hand and the manuscript of Athenaeus' Deipnosophistae on the other. Whereas Athenaeus' work was created as one whole and consistently copied as such, most of our sources for Sappho quote her fragments within texts of a different nature.

When discussing fragments, Glenn Most writes the following: "However splendidly the fragment gleams, what fascinates us even more is the darkness surrounding it." ${ }^{2}$ The word fragment itself implies a (violent) separation of one piece from a larger whole. At the same time, the fragment is irrevocably and continually connected to the lost whole. In his 2003 work The Powers of Philology, Hans Ulrich Gumbrecht describes the relation between a researcher and his fragments in psychological terms. ${ }^{23}$ After establishing that a text is, in fact, a fragment of a larger - but lost - whole, a series of events occurs in our minds. Unconsciously, but inevitably, the reader will construct a whole in his imagination. From that moment onward, this imaginary whole remains - often unconsciously - a point of reference in the reading of the fragment. ${ }^{24}$ Gumbrecht bases this argument on Sartre's L'imaginaire, ${ }^{25}$ which states that every imagined picture or text is by default whole.

Only by scrupulously applying new evidence to this image will it be possible to add details and change it. ${ }^{26}$ For Sappho, the two factors that most allow for new input are dialect and metre. These are often adduced as an objective means to reach a better reading of the fragments. Most agrees with Gumbrecht that imagination plays as large a role as erudition in our study of textual fragments. ${ }^{27}$ When confronted with a fragment, we construct a lost whole, subsequently - and unconsciously - leaving the fragment to one side in further study. The reason this constructed whole interests us, Most argues, is that it is the least fleeting. As far as we can establish, the original text has perished; and

\footnotetext{
$22 \quad$ Most (2009) 18.

23 Hans Ulrich Gumbrecht, "Identifying Fragments," in: idem, The Powers of Philology. Dynamics of Textual Scholarship (Chicago, 2003), pp. 9-23. Gumbrecht published an earlier version of the chapter "Identifying fragments": “Eat your fragment!," in: Glenn W. Most (ed.), Aporemata I: Collecting Fragments - Fragmente Sammeln (Göttingen, 1997) 315-27.

24 Gumbrecht (2003) 16.

25 Sartre (1940).

26 Gumbrecht (2003) 16-18.

27 Most (2009) 18.
} 
even the fragment that weathered the ages is more ephemeral than the image we constitute in our heads. ${ }^{28}$

Taking into account Most's ideas about the place of the whole in our study of fragments and Gumbrecht's comments about the role of our imagination, it is clear that there is a distinct tendency towards the speculative in the study of fragments. Gumbrecht and Most show us convincingly that every analysis is directed by preconceptions about the whole that is hidden behind the fragment. When studying fragments, we study nothing more - and nothing less than the image we have conjured up in our heads. If their intuition is right, it explains why the focus of classical philology has for so long been the attempt to $(\mathrm{re})$ construct these imagined wholes.

Textual fragments, then, form tricky primary sources, but for Sappho the textual fragments are fragmentary in another sense. Besides giving only part of the supposed original, fragments of Sappho's songs give only text, and often no hint of the other dimensions of the song: music, dance, and occasion. There is no evidence that the archaic lyric composers like Sappho wrote down their work. Even if they did, however, their work probably circulated largely in performance, rather than on paper, at least until the late fifth century вс. ${ }^{29}$ Each song was sung and heard in a different place and time. From then on it may well have been re-performed several times before someone saw reason to write down the lyrics. It is impossible to establish exactly what happened to individual songs during this stage in the transmission, but the status of the songs (evidenced by the simple fact that they survived as long as they did) will probably have guaranteed a rather close adherence to the original in re-performance. Still, a number of factors may have intruded at any point to change the text of a song in several ways, be it consciously through adaptation or unconsciously through mistakes.

The last two points form the crucial difference between the transmission of Sappho's songs and Athenaeus' Deipnosophistae. Firstly, Sappho's songs were reperformed in venues different from those originally intended and by new interpreters, mostly in a sympotic atmosphere, as described above. As a result, (parts of) her songs will have been performed out of context and with different

28 However, since the whole we construct is connected both to the mind that "conjured it up," (Gumbrecht (2003) 18) and to the fragment that provided the stimulus for the construction, every single reading of a fragment is unique, making the imagined whole it produces in fact extremely ephemeral.

29 See for the case of Sappho Lardinois (2008), and more generally Thomas (1992), Robb (1994) 4on23 for notes on corpora of oral poetry and passim for the slow advent of widespread written transmission for poetry in Greece, and Ford (2003). 
goals than originally intended: every single reperformance was unique and could have had an effect on later textual renderings. Secondly, if we believe, as I do, that written versions of compositions of archaic lyric poets did not circulate early on, then there is a distinct possibility that written versions would have been made after aural reception, probably from memory. Despite the fact that the Greeks would have been more used to this practice than we are, this process would have led to mistakes, and hence to variations. ${ }^{30}$

Athenaeus' Deipnosophistae, conversely, was preserved in a manuscript, transmitted as a whole, at least for the parts where Sappho is quoted. The main problem of fragments - the fact that they are fragmentary - is thus not an issue at all; none of the researchers' efforts need go into the reconstruction of a lost context. Since it was not quoted partially, but transmitted with the intention of reproducing it as a whole, there is no reason to assume that the scribe had specific reasons to present a deceptive image of the text. Finally, there can be no doubt that by the second century AD, Athenaeus composed his prose with writing in mind, either recording it himself or dictating to a scribe. The only serious obstacle separating the modern reader from the original work, then, is the fact that the manuscript went through several centuries of copying before reaching the tenth century, when our earliest extant manuscript was produced. There can be no doubt, however, that this problem is of a different nature to those created by the transmission of Sappho's songs in antiquity.

So the main problems that one encounters when researching the fragments of Sappho's songs do not apply (or at least do so to a lesser extent) to Athenaeus' Deipnosophistae. This is applicable for the whole of the text, irrespective of whether it is a quotation or part of the main narrative. The most important advantage is that the greater quantity of material provides an opportunity to use internal evidence in the analysis. For example, if the form of one stanza by Sappho quoted in Athenaeus is corroborated by external evidence, while another quote diverges significantly from the passage as found elsewhere, or from the metre as reconstructed, it is not economical to posit that in the second case scribal error must be the cause. Rather, it urges us to consider the possibility that either Athenaeus or his source changed the passage, again either intentionally or by accident.

30 Rubin (1995) 188 shows that even if someone attempts to faithfully reperform a song, in this case five songs by The Beatles, mistakes of a limited kind will be made. See also Lardinois (2006) who adduces English nursery rhymes to show how variation may make its way from oral into written versions. 
Papyrus finds demonstrate that in Athenaeus' time full editions of Sappho's songs were available in Egypt, where he himself worked. ${ }^{31}$ Athenaeus thus had the practical means to quote from these editions any song by Sappho, and he is shown to do so for the largest part of his quote of fragment $2 \mathrm{~V}$. Whenever the form of the fragment gives us reason to believe he diverged from this norm, then, we are challenged to establish what reasons he might have had. Errors in transmission are always possible, but they cannot easily account for large divergences.

After an exposition of the method, the following question might still be asked: New Philology - what's new? ${ }^{32}$ In the end, nothing in the methodology or theoretical framework is fundamentally new, since all "new philologists" are essentially repeating the work of other philologists. What I can say in their - or should I say our - defence is that we do more of this work. Philologists have paid attention to fragments and divergent versions of texts - in fact they are the ones who found them in the first place. Their attention has, however, been focused upon comparison with a view to reconstruction in the majority of cases. New Philology proposes to make the research into those fragments that are normally consigned to the darkness more visible. Readings that have been for some reason regarded as divergent, defective, or "absurd and unmetrical" are picked up again and re-appraised. ${ }^{33}$ By making them not marginal but central evidence, they are brought back to the light and asked to yield whatever information they might give us. Instead of asking: what is the relation of the fragment to the original? We might ask: what is the relation between its form and its owner? Or: what can the language tell us about its transmission? What does the co-existence of different variants in roughly the same time and place (in this case second-century Roman Egypt) mean for the attribution of the fragment or perhaps for the consciousness about authorship in general?

Although Sappho composed in the sixth century BC, the Alexandrian edition(s), ${ }^{34}$ created some time in the third and second centuries $\mathrm{BC}$, are the

$31 \quad$ This is suggested by the care with which they were created, the general uniformity of dialect and the presence of book numbers and author's name. Most notably papyri P. Oxy 1787 and 1231 show a great deal of editorial influence in, for example, the order of the songs and normalization of forms. Athenaeus worked in Naucratis.

32 I gratefully borrow this turn of phrase from D'Angour (2006). Note also Schnell (1997): "Was ist neu an der 'New Philology?"

33 As claimed by Maehler of some variants in a discussion of new fragments of Pindar's Epinicians in the 2010 Oxyrhynchus edition, pages 63 ("corrupt and excessive reading"), 64 ("unmetrical nonsense"), and 67 ("absurd and unmetrical").

34 For Alcaeus, a source mentions two separate editions, so the same possibility cannot be excluded for Sappho. 
best point of reference for the form of her songs. This canonical compilation formed the basis for a strong textual tradition that appears to have remained largely intact at least until the third century AD. It is very probable that we have parts of copies of this edition in some of the Sappho papyri found in and around Oxyrhynchus. ${ }^{35}$ These fragments present a predominantly consistent text as regards metre and dialect, and were available to the people at large and to scholars in particular. A significant divergence from the standard version in this period must therefore be regarded as marked in some way. Rather than cull the divergent elements of these "wild" fragments, they may be used more productively to establish the form of Sappho's songs in the time that the sources themselves were written. ${ }^{36}$

Let us consider one more case that illustrates the vicissitudes of the transmission of Sappho's songs, and how they were quoted. The Greek metrician Hephaestion wrote a book on metre in about the same period as Athenaeus worked. As mentioned before, Sappho's songs were marked not only by metrical form, but also by the peculiar Lesbian dialect she probably composed in. This dialect was something alien to the second-century speaker of Greek, and probably for them only accessible through the Alexandrian editions of the Lesbian composers. ${ }^{37}$ It is assumed that later authors had a tendency to change the language of Sappho's songs when they quoted her in their works. Instead of retaining the curious dialect from Lesbos - which they possibly did not fully understand themselves - they changed it to Attic, the dialect of Athens and later established as the standard throughout the greater Greek empire. ${ }^{38}$ The attitude of different authors towards the dialect may help us understand the form that was current in the second century, or at least what the proficiency of the authors was at that time.

35 See note 25 above.

36 I borrow the term from Homeric scholarship, where there is a group of early (Ptolemaic) papyri containing divergent, often otherwise unknown readings of the Iliad or Odyssey. For that reason they have become known as "eccentric" or "wild" papyri. See S. West (1967) for a survey of a group of such fragments.

37 The nature of the actual sixth century вС Lesbian dialect, however, is not completely known (see Hooker (1977) and Bowie (1981) for discussions). Moreover, her songs were also influenced by epic, which may well explain many of the non-Lesbian forms we find in her lyric. Late inscriptions show that the dialect as used on Lesbos itself had changed significantly by the fourth century BC already.

38 That there was a standard language does not mean this was always attained, $c f$. Versteegh (1987). See for the atticization of Sappho the note in Yatromanolakis (2007) 346. 


\author{
Hephaestion, Encheiridion XI, 3 P. Oxy, 220, col. IX, 12-13

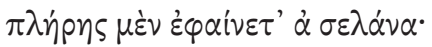

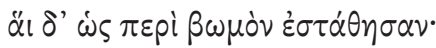 \\ $\mu \varepsilon \nu \varepsilon \varphi \alpha เ v \varepsilon \theta \alpha \sigma \varepsilon \lambda \alpha \nu \alpha$
}

The moon shone full, and they stood as if around an altar
The moon shone,

This fragment of a song attributed by Hephaestion to Sappho is known in two different forms. The divergence relevant to this analysis is the unaspirated $\tau$ (tau) in the Hephaestion manuscript, as opposed to the aspirated form $\theta$ (theta) in the papyrus. Lesbian was described as a psiloted, "hairless," dialect, meaning it did not know initial aspiration. ${ }^{39}$ In Attic and most other dialects, the article $(\dot{\alpha}, h a)$ is aspirated, which here has an effect on the last letter of the preceding word in elision. The aspiration extends to the preceding tau, producing a theta, as we find it in the papyrus fragment.

The rest of the fragment, in both sources, does show remainders of the Lesbian dialect, but not consistently. ${ }^{40}$ The key fact about this pair of variants is that it shows a late manuscript preserving the older, probably correct reading, whereas a much earlier papyrus source contains a form adapted to the then current language. The Hephaestion text shows us that at least in some manuscripts Lesbian forms have survived the centuries of transmission. The chance that this form was changed back to Lesbian at a later time in the transmission is much smaller than that it was preserved - for whatever reason - while other forms were "simplified" into the Attic form. This line of reasoning raises the possibility that Hephaestion, writing on metre, was consistent in quoting Sappho in the Lesbian form. If that was the case, it shows that some authors at least had no problem with the peculiar dialect.

At the same time, we have a papyrus from the second century that cites a line that seems to have been adapted to the Attic form. Since we can assume that the correct forms were both available and actually still in use, then the form on the papyrus may argue for the atticization that is so often posited, but it is one of only a very few atticized forms found on ancient papyri. The papyrus contains an anonymous treatise on metre, just like Hephaestion's booklet. If one were to look for a reason to explain the unusual Attic form found in so

\footnotetext{
39 Cf. Hooker (1977) 18, and Bowie (1981) 51-52.

40 The alpha instead of the êta in both the article and the noun selênê are un-Attic, but in all probability (the evidence is not conclusive) the Lesbian form would have been selanna, with a double $n u$.
} 
early a source, one might consider that the line had become a rote verse to explain a certain kind of metre. This would then probably have been transmitted orally, as an often-used example, until finally it was written down out of context, having lost - as far as the author of the papyrus is concerned - most of its connection to its author and her Lesbian dialect.

Whereas Gumbrecht and Most were concerned with the nature of fragments in theory, the practice is even more problematic because our imagination is not only let loose on the dark surrounding the fragment, but also on the contents of the fragments itself. In the case of Sappho's fragments some of its metaphysical surroundings are not quite so dark; that is to say, we have an idea about the context. This regards form (metre and dialect), generic context, and in some cases even co-text. This darkness embodied threatens to overshadow the small point of light that is the fragment in many cases. Just as a fragment may give a skewed view of its context, so context might intrude upon the fragment to such an extent that its immanent characteristics are lost.

For Sappho, as for many of the other composers known only through fragments, there is a tendency to thrust the general upon the particular. The scarce knowledge extrapolated from the collective of fragments and testimonia over time becomes the reference point for the assessment and reconstruction of every individual fragment. I do not question the validity of this method, but I do have a problem with where this method has left the fragments themselves. Their original form has become completely subordinate to their place in the reconstructed corpus. This happens to such an extent that editions of Athenaeus' Deipnosophistae will give a quote from Sappho in its emended form so as to "faithfully" represent the reconstructed original. ${ }^{41}$ This creates a very undesirable situation, as the reader is presented with a text of Athenaeus that the ancient (and intended) reader most probably never heard of or laid eyes on.

Even if Athenaeus did not know Sappho's songs in their original form, he would have had recourse to the standard editions that we know were available in his time. He should therefore have been able to reproduce the songs at least in a consistent way. As for the transmission of Athenaeus and the quotations of Sappho contained within it, the transmission would probably have been a bumpy ride for the lines in the curious Lesbian dialect; scribes writing scriptio continua would have made identifications of quotations very hard, and understanding for later copyists would not have been aided thereby. The mistakes we

41 See Olson (2009) (volume 5) 224; Gulick in his 1933 Loeb edition, volume 5 page 20, does the same, but at least he notes most emendations in his apparatus. Meinecke's 1858 edition, volume II page 340, stays closer to the A manuscript, but he completely changes the last line of Sappho $2 \mathrm{~V}$. in an attempt to match the metre. 
expect, and find, are mostly of an orthographic nature, ${ }^{42}$ and are possibly some well-intended corrections by scribes. More substantial differences can still be the result of the copying process, but often they may be explained otherwise, especially if the text they yield has not become nonsense.

When we quote someone, especially in conversation, our attitude towards reality is often loose. This is in many cases not done with an eye on twisting what was actually said, but rather because the point we wish to make is unconnected to the exact form it comes in, while we do wish to claim a connection with an authority. Or, conversely, when quoting a song we may remember the melody very well, but have a more liberal attitude towards the lyrics. It is this kind of quoting that we might expect to have led to many of the divergences in form that we find in later quotes of Sappho's songs.

I would conclude that with regard to Sappho's songs, even the first eight centuries of transmission inevitably left their mark. Even after the standardization of the text at some point in the third century $\mathrm{BC}$, the modes of transmission would have remained diffuse. There is no reason to assume that each fragment of Sappho's songs we find in other authors or even on papyri should have had the form that is found in the standard edition. If we accept this not wholly counterintuitive premise, we may find peace with some of the apparently defective fragments of Sappho that we find, accepting them as the result of different kinds of transmission. These different kinds of transmission were fuelled by different kinds of motivation and created in divergent environments. Some songs, or parts of them, may have roughly retained their intended forms through continuous oral transmission. For others the form would have been lost in time, even if the accompanying lyrics were preserved in writing. Once this dissociation had taken place, it was but a small step to changes in the wording and in some cases a complete loss of the metrical form.

The diversity of the fragments we find in sources from the early centuries of our era reflects both the different means through which Sappho's songs were transmitted and the attitude of individual authors towards them. If we reconsider the divergent forms of her songs, we may not come closer to hearing her sixth-century BC compositions, but we may find first-hand accounts of people who still had access to most of her songs, in whatever form, and establish what they found in her songs that made them worth recording.

42 An interesting case is Sappho fragment 55 V., which is quoted twice in Plutarch's Quaestiones, in different forms, and in a third form in Stobaeus' Anthologia. 


\section{References}

Bowie, A.M., The poetic dialect of Sappho and Alcaeus (New York, NY, 1981).

Cerquiglini, B., Éloge de la variante: Histoire critique de la philologie (Paris, 1989).

Collins, D., Master of the game (Washington, 2004).

D’Angour, A., "The New Music: So what's new?," in Rethinking Revolutions through Ancient Greece, eds. S. Goldhill and R. Osborne (Cambridge, 2006), pp. 264-83.

Ford, A., "From Letters to Literature. Reading the 'Song Culture' of Classical Greece," in Written Texts and the Rise of Literate Culture in Ancient Greece, ed. H. Yunis (Cambridge, 2003), pp. 15-37.

Greene, E. and M.B. Skinner, eds., The New Sappho on Old Age (Cambridge, MA, 2009). Gumbrecht, H.U., "Eat your fragment!" in Aporemata I: Collecting Fragments - Fragmente Sammeln, ed. G.W. Most (Göttingen, 1997), pp. 315-27.

-

Hadjimichael, Th. A, Bacchylides and the Emergence of the Lyric Canon (unpublished thesis, University College London, 2011).

Hooker, J.T., The language and text of the Lesbian poets (Innsbruck, 1977).

Lardinois, A.P.M.H., "Subject and Circumstance in Sappho's Poetry," in Transactions of the American Philological Association 124 (1994) 57-84.

___ "Have we Solon's verses?" in Solon of Athens: new historical and philological approaches, eds. J. Blok and A. Lardinois (Leiden, 2006), pp. 15-35.

___ ' "Someone, I say, will remember us': Oral Memory in Sappho's Poetry," in Orality, Literacy, Memory in the Ancient Greek and Roman World, ed. A. MacKay (Leiden: Brill 2008) 79-96.

- - "New Philology and the Classics: Accounting for Variation in the Textual Transmission of Greek Lyric Poetry," in The Reception of Greek Lyric Poetry 6оовс40oAD: Transmission, Canonization, and Paratext, eds. B. Currie and I. Rutherford. Proceedings of the Network for the Study of Archaic and Classical Greek Song, Vol. 3 , forthcoming.

Maehler, H and M. Buchholz, The Oxyrhynchus Papyri 75 (London, 2010).

Most, G.W., ed., Collecting Fragments/Fragmente Sammeln (Göttingen, 1997).

Most, G.W., "On Fragments," in The Fragment: An Incomplete History, ed. W. Tronzo (Los Angeles, CA, 2009), pp. 8-20.

Nichols, S.G., "Introduction: Philology in a Manuscript Culture," in Speculum 65 (1990), pp. 1-10.

Nicosia, S., Tradizione testuale diretta e indiretta dei poeti di Lesbo (Rome, 1976).

Olson, S.D., Athenaeus. The Learned Banqueters. Edited and Translated by S. Douglas Olson (2006-2012).

Parker, H.N., "Sappho Schoolmistress," in Transactions of the American Philological Association 123 (1993), pp. 309-51. 
Reitzenstein, R., Epigramm und Skolion (Giessen, 1893).

Robb, K., Literacy and paideia in ancient Greece (Oxford, 1994).

Rubin, D.C., Memory in oral traditions (New York, NY, 1995).

Sartre, J.-P., L'imaginaire: psychologie phénoménologique de l'imagination (Paris, 1940).

Schnell, R., "Was ist neu an der 'New Philology'?" in Alte und neue Philologie, eds. M.-D.

Gleßgen and F. Lebsanft (Tübingen, 1997), pp. 61-95.

Stackmann, K., "Neue Philologie?" in Modernes Mittelalter: Neue Bilder einer populären Epoche, ed. J. Heinzle (Frankfurt am Main, 1994), pp. 398-427.

Versteegh, K., "Latinitas, Hellenismos, Arabiyya," in The History of Linguistics in the Classical Period (Amsterdam, 1987), pp. 251-74.

Vetta, M., Poesia e simposio nella Grecia antica (Bari, 1995).

Voigt, E.-M., Sappho et Alcaeus. Fragmenta (Amsterdam, 1971).

West, S., The Ptolemaic papyri of Homer (Cologne, 1967).

Yatromanolakis, D., Sappho in the Making. The early reception (Washington, DC, 2007).

Zumthor, P., Essai de poétiqui mediévale (Paris, 1972).

—_, Introduction á la poésie orale (Paris, 1983). 